\title{
Zinc Deficiency-induced Hypogeusia in a Patient with Refractory Iron-deficiency Anemia: A Case Report
}

\author{
Alex J. Gooding ${ }^{1}$, Clifford D. Packer ${ }^{1}$, Amanda L. Pensiero ${ }^{1,2}$ \\ 1. Internal Medicine, Case Western Reserve University School of Medicine, Cleveland, USA 2. Internal Medicine, Louis \\ Stokes Cleveland Veterans Affairs Medical Center, Cleveland, USA
}

Corresponding author: Alex J. Gooding, ajg126@case.edu

\begin{abstract}
Zinc deficiency is a relatively common condition in various American populations but is frequently unrecognized and under-diagnosed. It typically presents with nonspecific symptoms, including lethargy, immune dysfunction, dermatitis, diarrhea, and decreased taste sensation (hypogeusia). Zinc deficiency often occurs concurrently with iron deficiency and has been linked to more severe clinical manifestations of iron deficiency anemia. We describe a 66-year-old man who presented with weakness and fatigue and was found to have persistent iron-deficiency anemia attributable at least in part to malnutrition caused by zinc deficiency-induced hypogeusia. The hypogeusia rapidly improved and nutritional intake normalized with zinc supplementation.
\end{abstract}

Categories: Internal Medicine, Hematology

Keywords: iron-deficiency anemia, hypogeusia, taste disturbances, malnutrition, oral zinc supplementation, zinc deficiency

\section{Introduction}

Zinc is a biologically essential and ubiquitous trace mineral found in a wide array of food such as shellfish, red meat, seeds, and fortified grains [1]. Despite its abundance, the prevalence of inadequate zinc intake worldwide has been estimated at $17 \%$, with $35 \%$ to $45 \%$ of American adults over the age of 60 not meeting the recommended daily zinc requirement [2-3]. Clinical manifestations of zinc deficiency are multifold and nonspecific but often include disturbances in taste perception. We present the case of a zinc-deficient man found to be objectively undernourished in the setting of a longstanding state of hypogeusia that abruptly improved upon zinc supplementation.

\section{Case Presentation}

Received 10/02/2019 Review began 10/03/2019 Review ended 12/10/2019 Published 12/12/2019

๑ Copyright 2019 Gooding et al. This is an open access article distributed under the terms of the Creative Commons Attribution License CC-BY 3.0., which permits unrestricted use, distribution, and reproduction in any medium, provided the original author and source are credited.
A 66-year-old African American man presented with a two-week history of worsening fatigue and generalized weakness and was found to have severe microcytic anemia with hemoglobin $5.3 \mathrm{~g} / \mathrm{dL}$ and mean corpuscular volume $57.8 \mathrm{um}$. Iron deficiency anemia (IDA) was confirmed with a ferritin of $2 \mathrm{ng} / \mathrm{ml}(25-250$ $\mathrm{ng} / \mathrm{ml}$ ). His medical history was significant for IDA of unknown origin, hepatitis C previously treated with ledipasvir/sofosbuvir, right frontal lobe stroke, GOLD II chronic obstructive pulmonary disease (COPD), hypertension, and hyperlipidemia. He denied abdominal pain, melena, hematochezia, dysphagia, odynophagia, hematuria, hemoptysis, or abnormal bruising. He described a four-to-five-year history of persistent hypogeusia for all foods, which made it difficult for him to eat even when he felt hungry. Of note, he had been admitted two years before for similar symptoms, at which time IDA was first diagnosed. He underwent colonoscopy and esophagogastroduodenoscopy at that time, which revealed only internal hemorrhoids and mild gastritis. At that time, he was prescribed an oral iron supplement but adherence was inconsistent due to mild gastrointestinal symptoms. Small-bowel follow-through, push enteroscopy, nor capsule endoscopy was performed throughout the course of his presentation.

On physical exam, the patient was cachectic with temporal and supraclavicular wasting; the body mass index (BMI) was 18.4. Vital signs were normal. There was no cervical, axillary, or inguinal lymphadenopathy. There were diffuse expiratory wheezes and a $2 / 6$ systolic ejection murmur at the upper left sternal border; the abdomen was soft and nontender, with no masses and no enlargement of the liver or spleen. There was no jaundice and no rashes or other skin lesions and no peripheral edema. The neurologic exam was nonfocal.

Additional laboratory testing revealed white blood cells (WBCs) $4.5 \times 109 / \mathrm{L}$, platelet count $332 \times 109 / \mathrm{L}$, serum iron $6 \mu \mathrm{g} / \mathrm{dL}$, total iron-binding capacity (TIBC) $394 \mu \mathrm{g} / \mathrm{dL}$, TIBC\% 2, reticulocyte count $1.41 \%$, and normal lactate dehydrogenase (LDH), haptoglobin, creatinine, electrolytes, and liver function tests. The peripheral blood smear (Figure 1) was notable for microcytosis, with prominent erythrocytic central pallor. The patient was transfused two units of packed red blood cells with an incremental increase in his hemoglobin to $7.8 \mathrm{~g} / \mathrm{dL}$. 


\section{Cureus}

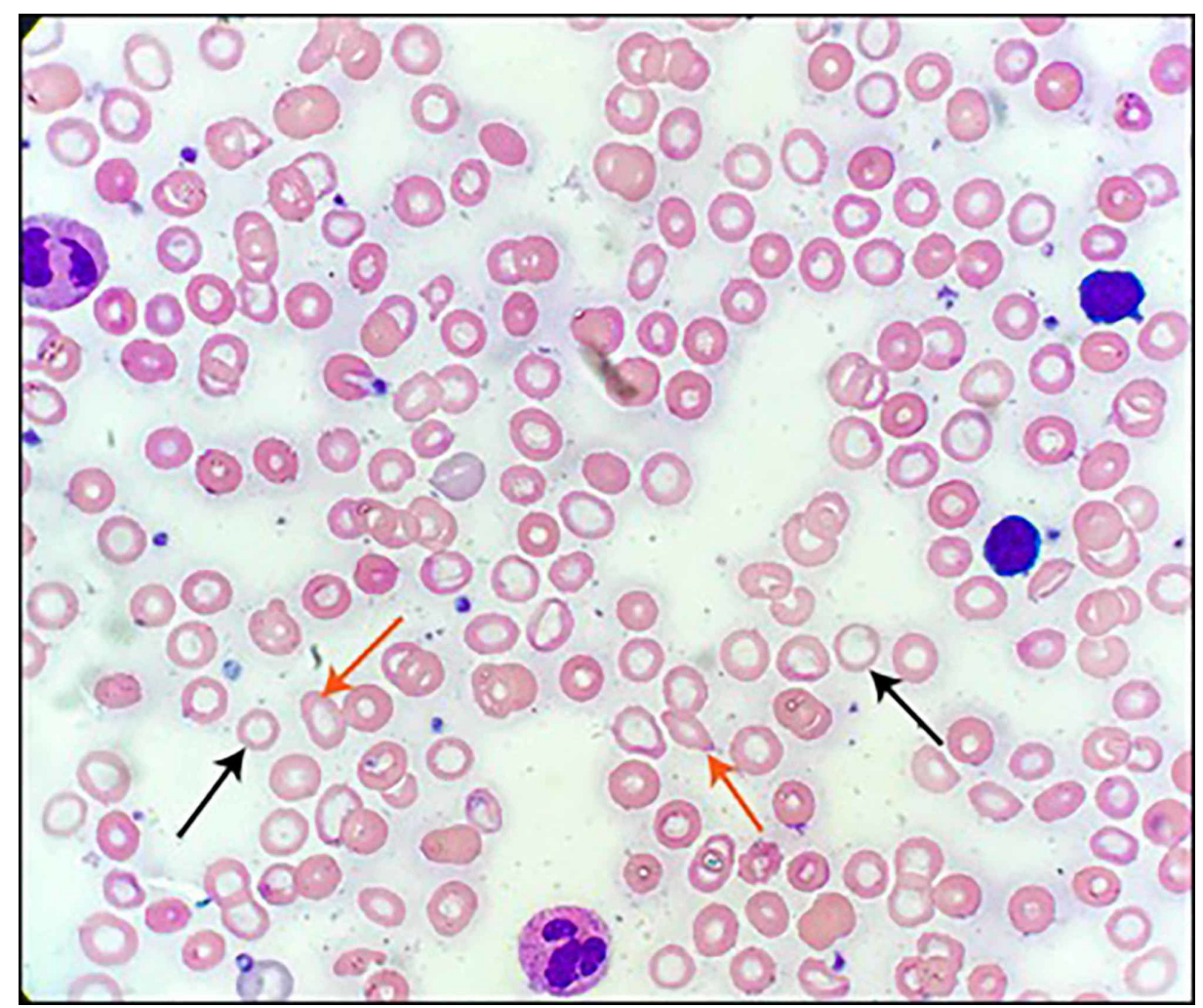

FIGURE 1: Peripheral blood smear of the patient upon presentation

Evidence of marked hypochromia (black arrows) and microcytosis, as well as anisopoikolocytosis (red arrows)

A nutritional analysis obtained via a detailed dietary history revealed inadequate daily caloric intake, as well as insufficient quantities of all macro- and micronutrients, including zinc (Table 1). Zinc deficiency was confirmed with a serum zinc level of $52 \mu \mathrm{g} / \mathrm{dl}$ (70-150 $\mu \mathrm{g} / \mathrm{dL})$. In addition to oral iron supplementation, he was started on a multivitamin with zinc and discharged to home. At follow-up 19 days after discharge, the patient described a significant improvement in his fatigue and weakness and a rapid restoration of his sense of taste, which had led to increased nutritional intake and a $2.3 \mathrm{~kg}$ weight gain. 


\section{Cureus}

\begin{tabular}{|c|c|c|}
\hline Nutrient & Daily Total & Reference Total (51-70 y/o male) [4] \\
\hline Kcal & 436 Kcal & $2000 \mathrm{Kcal}$ \\
\hline Protein & $18.4 \mathrm{~g}$ & $40 \mathrm{~g}$ \\
\hline Carbohydrate & $65 \mathrm{~g}$ & $210-303 \mathrm{~g}$ \\
\hline Fat & $12 \mathrm{~g}$ & $41-73 \mathrm{~g}$ \\
\hline Sodium & $632 \mathrm{mg}$ & $1500 \mathrm{mg}$ \\
\hline Potassium & $521 \mathrm{mg}$ & $3400 \mathrm{mg}$ \\
\hline Calcium & $45 \mathrm{mg}$ & $1000 \mathrm{mg}$ \\
\hline Phosphorus & $306 \mathrm{mg}$ & $700 \mathrm{mg}$ \\
\hline Iron & $1.8 \mathrm{mg}$ & $8 \mathrm{mg}$ \\
\hline Zinc & $1.3 \mathrm{mg}$ & $11 \mathrm{mg}$ \\
\hline Magnesium & $32.7 \mathrm{mg}$ & $420 \mathrm{mg}$ \\
\hline Vitamin A & $54 \mu \mathrm{g}$ & $900 \mu \mathrm{g}$ \\
\hline Vitamin C & $15.6 \mathrm{mg}$ & $90 \mathrm{mg}$ \\
\hline Vitamin $E$ & $0.5 \mathrm{mg}$ & $15 \mathrm{mg}$ \\
\hline Vitamin B1 (thiamine) & $0.27 \mathrm{mg}$ & $1.2 \mathrm{mg}$ \\
\hline Vitamin B2 (riboflavin) & $0.20 \mathrm{mg}$ & $1.2 \mathrm{mg}$ \\
\hline Vitamin B6 & $0.39 \mathrm{mg}$ & $1.7 \mathrm{mg}$ \\
\hline Vitamin B12 & $0.46 \mu \mathrm{g}$ & $2.4 \mu \mathrm{g}$ \\
\hline Folate & $45.11 \mu \mathrm{g}$ & $400 \mu g$ \\
\hline
\end{tabular}

TABLE 1: Estimation of the patient's total daily intake of various macro- and micronutrients based on the acquisition of a detailed dietary history obtained by dietetic specialists

Recommended daily value of each nutrient for males aged 51-70 listed in the right column

\section{Discussion}

Zinc is an essential trace mineral whose abundance among transition metal ions in all living organisms is second only to that of iron [5]. It functions as a cofactor or structural stabilizer for more than 300 enzymes throughout the body and directs a wide array of biochemical and cellular processes, including signal transduction, ribonucleic acid (RNA) transcription, and cellular growth, division, and differentiation [5-6]. Interestingly, patients with IDA have been shown to have significantly reduced serum levels of zinc while IDA is significantly more prevalent in patients known to have zinc deficiency [7-9]. More specifically, zinc deficiency has been speculated to contribute to the development of IDA through the inhibition of the intestinal absorption of iron as well as its mobilization from tissue stores [10].

Zinc deficiency can cause a variety of symptoms, including anorexia, lethargy, immune dysfunction, decreased wound healing, dermatitis, hypogonadism, and hypogeusia [11]. Our patient had weakness, fatigue, and weight loss, with a subnormal body mass index (BMI) and signs of cachexia on the physical exam. His long history of hypogeusia was a clear factor in the development of his malnutrition. Whether hypogeusia-induced malnutrition was the chief cause of his IDA is unclear. IDA is frequently seen in patients with negative upper and lower gastrointestinal (GI) endoscopic studies and is often attributed to small intestinal pathologies such as angiodysplasias, Crohn's disease, celiac disease, and jejunal or ileal adenocarcinoma. Our patient did not undergo diagnostic testing aimed at assessing such pathologies. However, our nutritional analysis, with an estimated $1.8 \mathrm{mg}$ daily iron intake (compared with the recommended daily intake of $8 \mathrm{mg}$ ), suggests that his IDA could have been entirely or largely a result of inadequate dietary iron. If dietary insufficiency was not the sole cause of his IDA, it was certainly a contributing factor. 
common hypogeusia (a diminished sense of taste) and dysgeusia (altered perception of taste) to the more rare ageusia, a complete loss of taste [12]. In the USA, the prevalence of taste disturbance in the general population is $17.3 \%$ [13], but the vast majority of cases are caused by primary disturbances of olfaction [14]. Primary gustatory deficiencies are more frequently associated with malnutrition and diminished quality of life and can have a variety of etiologies, including poor oral hygiene or oral infection, sequelae of surgery or radiation, medication (e.g., chemotherapeutic drugs, angiotensin-converting enzyme (ACE) inhibitors, angiotensin II receptor blockers, macrolides, fluoroquinolones, and anticonvulsants, among others), trauma, renal failure, cancer, and zinc deficiency [15].

The molecular underpinnings of zinc deficiency-mediated hypogeusia are not fully understood, but a generous body of research has tied this phenomenon to various isoforms of human salivary gland-specific carbonic anhydrase, a zinc metalloenzyme whose expression and function have been shown to depend on ample concentrations of zinc [16-18]. It has been postulated that zinc supplementation may restore taste sensation in patients with both idiopathic and zinc deficiency-associated taste disturbances. Although the results of clinical trials have been inconsistent, a comprehensive Cochrane meta-analysis reveals some evidence to support the use of zinc supplementation to treat taste disturbances as measured by objective descriptors of taste acuity, particularly in zinc-deficient cohorts [3,19-20]. Our zinc-deficient patient's chronic hypogeusia improved rapidly with zinc supplementation.

\section{Conclusions}

Concurrent zinc deficiency should be considered in the evaluation of iron deficiency anemia, especially in patients with taste disturbances. Hypogeusia from zinc deficiency can lead to significant nutritional deficiencies and may cause or aggravate iron deficiency.

\section{Additional Information}

\section{Disclosures}

Human subjects: Consent was obtained by all participants in this study. Conflicts of interest: In compliance with the ICMJE uniform disclosure form, all authors declare the following: Payment/services info: All authors have declared that no financial support was received from any organization for the submitted work. Financial relationships: All authors have declared that they have no financial relationships at present or within the previous three years with any organizations that might have an interest in the submitted work. Other relationships: All authors have declared that there are no other relationships or activities that could appear to have influenced the submitted work.

\section{References}

1. Ma J, Betts NM: Zinc and copper intakes and their major food sources for older adults in the 1994-96 Continuing Survey of Food Intakes by Individuals (CSFII). J Nutr. 2000, 130:2838-2843. 10.1093/jn/130.11.2838

2. Wessells KR, Brown KH: Estimating the global prevalence of zinc deficiency: results based on zinc availability in national food supplies and the prevalence of Stunting. PLoS One. 2012, 7:50568 10.1371/journal.pone.0050568

3. Pisano M, Hilas O: Zinc and taste disturbances in older adults: a review of the literature . Consult Pharm. 2016, 31:267-270. 10.4140/TCP.n.2016.267

4. Golder M: Dietary Reference Intakes for Calcium and Vitamin D . National Academies Press, Washington, D.C.; 2011. 10.17226/13050

5. Chasapis CT, Loutsidou AC, Spiliopoulou CA, Stefanidou ME: Zinc and human health: an update . Arch Toxicol. 2012, 86:521-534. 10.1007/s00204-011-0775-1

6. Beyersmann D: Homeostasis and cellular functions of zinc. Materwiss Werksttech. 2002, 33:764-769. 10.1002/mawe.200290008

7. Kelkitli E, Ozturk N, Aslan NA, et al.: Serum zinc levels in patients with iron deficiency anemia and its association with symptoms of iron deficiency anemia. Ann Hematol. 2016, 95:751-756. 10.1007/s00277016-2628-8

8. Ergul AB, Turanoglu C, Karakukcu C, Karaman S, Torun YA: Increased iron deficiency and iron deficiency anemia in children with zinc deficiency. Eurasian J Med. 2018, 50:34-37. 10.5152/eurasianjmed.2017.17237

9. Abdelhaleim AF, Amer AY, Abdo Soliman JS: Association of zinc deficiency with iron deficiency anemia and its symptoms: results from a case-control study. Cureus. 2019, 11:3811. 10.7759/cureus.3811

10. Kondaiah P, Yaduvanshi PS, Sharp PA, Pullakhandam R: Iron and zinc homeostasis and interactions: does enteric zinc excretion cross-talk with intestinal iron absorption?. Nutrients. 2019, 11:1885. 10.3390/nu11081885

11. Hambidge M: Human zinc deficiency. J Nutr. 2000, 130:1344-1349. 10.1093/jn/130.5.1344S

12. Brand JG: Within reach of an end to unnecessary bitterness? . Lancet. 2000, 356:1371-1372. 10.1016/S01406736(00)02836-1

13. Liu G, Zong G, Doty RL, Sun Q: Prevalence and risk factors of taste and smell impairment in a nationwide representative sample of the US population: a cross-sectional study. BMJ Open. 2016, 6:013246. 10.1136/bmjopen-2016-013246

14. Pribitkin E, Rosenthal MD, Cowart BJ: Prevalence and causes of severe taste loss in a chemosensory clinic population. Ann Otol Rhinol Laryngol. 2003, 112:971-978. 10.1177/000348940311201110

15. Malaty J, Malaty IAC: Smell and taste disorders in primary care . Am Fam Physician. 2013, 88:852-859. 


\section{Cureus}

16. Shatzman AR, Henkin RI: Gustin concentration changes relative to salivary zinc and taste in humans . Proc Natl Acad Sci U S A. 1981, 78:3867-3871. 10.1073/pnas.78.6.3867

17. Yagi T, Asakawa A, Ueda H, Ikeda S, Miyawaki S, Inui A: The role of zinc in the treatment of taste disorders . Recent Pat Food Nutr Agric. 2013, 5:44-51. 10.2174/2212798411305010007

18. Henkin RI, Mueller CW, Wolf RO: Estimation of zinc concentration of parotid saliva by flameless atomic absorption spectrophotometry in normal subjects and in patients with idiopathic hypogeusia. J Lab Clin Med. 1975, 86:175-180.

19. Michelson M, Veitz-Keenan A: Taste disturbances - are there any effective treatments? . Evid Based Dent. 2018, 19:60-61. 10.1038/sj.ebd.6401312

20. Kumbargere Nagraj S, George RP, Shetty N, Levenson D, Ferraiolo DM, Shrestha A: Interventions for managing taste disturbances. Cochrane Database Syst Rev. 2017, 10.1002/14651858.CD010470.pub3 